\title{
Awareness and implementation of lonizing radiation safety measures among urology community in Egypt: nationwide survey
}

\author{
Mohamed Omar', Esam E. A. Desoky², Basheer Elmohamady ${ }^{3}$, Alaa El-Shaer ${ }^{3}$ and Yasser A. Noureldin ${ }^{3 *}$ (i)
}

\begin{abstract}
Background: To assess awareness of ionizing radiation safety measures among Egyptian Urology Trainees and Urologists and see the effect of radiation safety courses on the adoption of these measures.

Methods: This Internet-based survey was conducted via https://www.surveymonkey.com/ after approval by the Egyptian Urological Association (EUA). It was sent to all EUA members via email during December 2019. Participation was voluntary and questions included participants' demographics such as age, gender, years of experience, level of training and type of practice. Other questions assessed some domains such as whether the participant had radiation safety courses, and the extent to which she/he is adopting these measures during daily practice.

Results: A total of 142 Egyptian urology trainees and urologists responded to this electronic survey. The mean hours of fluoroscopy-guided endourologic procedures per week were $4.3 \pm 2.1 \mathrm{~h}$, and only $23 \%$ reported that they always wear protective lead aprons. In terms of the thyroid shield, $X$-ray protective gloves, eye googles, a total of $70 \%$ and $89 \%$ and $89 \%$ reported that they never wore it, respectively. The ALARA principle was known by only $24 \%$ of respondents. About $94 \%$ denied receiving any radiation safety courses. Participants who received radiation safety course reported significantly shorter FT during URS ( $p=0.04)$, PCNL $(p=0.03)$ and JJ insertion $(p=0.04)$ and were significantly more compliant ( $p=0.02)$. In addition, the number of years of experience $(<5 y, 5-10 y, 10-15 y\rangle 15 y$,$) and the cur-$ rent job level (resident, specialist, consultant, professor) was significantly associated with higher compliance with lead aprons ( $p=0.006, p<0.001$, respectively). On regression analysis, previous radiation safety awareness courses were the only predictor of good compliance with radiation safety measures ( $\mathrm{OR}=2 \pm 0.73, p=0.009)$.
\end{abstract}

Conclusion: There was a lack of awareness and implementation of radiation safety measures among all participants. Receiving radiation safety courses was the only predictor of good compliance with radiation safety measures.

Keywords: Radiation, Egypt, Urologists, Trainees, Safety, Urology

\section{Background}

Over the past few decades, there was world-wide substantial increase in the prevalence of urologic diseases which require ionizing radiation either for diagnosis, treatment and follow-up. [1, 2]. In the United States, a report released by the NCRP (National Council on Radiation

\footnotetext{
*Correspondence: dryasser.noor@fmed.bu.edu.eg

${ }^{3}$ Department of Urology, Benha Faculty of Medicine, Benha University,

Benha 13511, Egypt

Full list of author information is available at the end of the article
}

Protection and Measurements) in 2009 showed that the higher numbers of Computed Tomography (CT) scans, nuclear medicine, radiotherapy and fluoroscopy guided procedures have doubled the ionizing radiation exposure during 2006 compared with 1980s [3, 4]. Despite the fact that ionizing radiation plays crucial role in the modern urology practice, it is associated with potential hazards, either from direct cell death while applying high dose to sensitive organs such as skin and eye lens, or from DNA mutation which result in malignancy when cumulative 
low doses are applied [5-7]. In 2015, two recent studies, one in the Lance Hematology and one in the British Medical Journal, reported direct and linear association between malignancy and protracted low dose ionizing radiation exposure among more than 300,000 radiation workers from USA, UK and France [8, 9].

Researchers and organizations did a lot of work to put regulations to keep ionizing radiation exposure to the minimum, such as the ALARA concept ("As Low As Reasonably Achievable [10], or modifying the diagnostic techniques such as the low-dose CT scan [11], or modifying the interventions to be performed with lower radiation using pulse fluoroscopy during URS and PCNL [12], or without radiation at all such as the Fluoroless Ureteroscopy [13], and Ultrasound-guided PCNL [14].

Several studies have shown a lack of awareness and implementation of radiation safety measures among European, American and Indian urology trainees [1517]. Similarly, other reports showed the same findings among Turkish and Brazilian operating room staff [18, 19]. However, there is no data about the awareness and implementation of ionizing radiation safety measures among Egyptian trainees and urologists. Therefore, the purpose of this study was to assess this item and see whether radiation safety courses has an effect on adoption of radiation safety measures. Our hypothesis was that there is a lack of awareness, training and implementation of radiation safety measures among Egyptian trainees and urologists and radiation safety courses could increase the compliance with radiation safety measures.

\section{Methods}

\subsection{Study design}

This Internet-based survey was created and delivered via a secure website https://www.surveymonkey.com/. After being approved by the Egyptian Urological Association (EUA), this survey entitled "Urologist Radiation Protection Concepts during Fluoroscopy-guided Urological Interventions in Egypt" was sent to all EUA members via email during late December 2019 and Early January 2020. There was a notice that participation is appreciated, but not compulsory, and data will be used to check the necessity for establishing radiation safety protocols by the EUA and will be published as a research article.

The survey included 34 questions, and data collected were accessed only by the investigators without any personal identifiable information. The survey looked at participants' demographics including age, gender, years of experience, level of training, and type of practice. Other questions about knowledge of radiation hazards and the awareness, training, and implementation of ionizing radiation safety measures were included (The questions could be accessed from the following link https://www.surve
ymonkey.com/r/823RVW5). Other direct questions were included to ask about the knowledge of ALARA principle, whether the wear of Lead aprons is mandatory per hospital regulations, whether the weight of lead aprons can refrain participants from wearing it, whether a food is supplied to those at higher risk for radiation exposure, and the experience of witnessing a nurse or a urologist being treated for $\mathrm{X}$-ray exposure related disease.

\subsubsection{Statistical analysis}

Data were collected from the Survey Monkey, tabulated and analyzed using the SPSS version 22 from IBM. The Chi square test was used to compare different categorical variables, and Kruskal Wallis test was used to compare FT among different categories of participants, and Mann-Whitney U test was used to compare FT among participants who received radiation safety course and those who did not receive radiation safety course. All two tailed $p$ values $<0.05$ were considered statistically significant.

\section{Results}

A total of 142 urology trainees and urologists responded to this electronic survey. Data regarding respondents' demographics, current job level and years in practice are reported in Table 1.

Specialists represented more than $40 \%$ of our respondents, followed by consultants $24 \%$. The mean hours of fluoroscopy guided endourologic procedures per week were $4.3 \pm 2.1 \mathrm{~h}$. Most of urologists have been practicing or closely participating 4 (2.75-6) URS, 1(1-2) PCNL and 5(2-6) double J insertion per week. The average Fluoroscopy time (FT) was $125 \pm 177 \mathrm{~s}$ per URS, $396 \pm 542 \mathrm{~s}$ per PCNL and $62 \pm 100$ s per Double J insertion.

Regarding wearing protective lead apron during $\mathrm{C}$-arm exposure, $23 \%$ reported that they always wear it, $38 \%$ sometimes wear it, and $13 \%$ rarely wear it. In terms of the thyroid shield and X-ray protective gloves and eye googles, $70 \%$ and $89 \%$ and $89 \%$ reported that they never wear it, respectively (Fig. 1).

About 91\% of urologists reported that they are not obligated to wear these radiation protective shields by their hospital regulations and more than $94 \%$ denied receiving any radiation safety course by their institutions. Only $45 \%$ have reported reading a manuscript about methods of radiation protection, while $18 \%$ have participated in trials of using dosimeters for calculation of the estimated radiation exposure during different surgeries. The ALARA principle was known by only $24 \%$ of respondents. Seventy percent of participants chose gonads as the most sensitive organ to radiation, and $62 \%$ chose computerized tomography urinary tract (CTUT) as the imaging modality associated with highest radiation exposure (Table 1). 
Table 1 Baseline demographics of participants and demographics of radiation safety procedures and awareness

Variable

Number

(percentage)

Age

25-34

$52(37)$

35-44

$53(38)$

45-54

$21(14)$

55-64

$13(9)$

$65+$

Years in practice of urology

$<5$ years

5-10 years

10-15 years

$>15$ years

Current job level

Resident

Specialist

Consultant

Professor

Comorbidities

Diabetes

Hypertension

Hyperuricemia

Others

Are you obligated to wear these things by your hospital or not? Yes

Did you take any radiation safety course by your hospital? Yes

Have you ever read a manuscript about methods of radiation protection for Endourologists? Yes

Have you ever participated in using dosimeters for calculation of the estimated radiation exposure during different Endourologic

Do you know ALARA principle? Yes

Do you complain about the weight of the lead apron shield? Yes

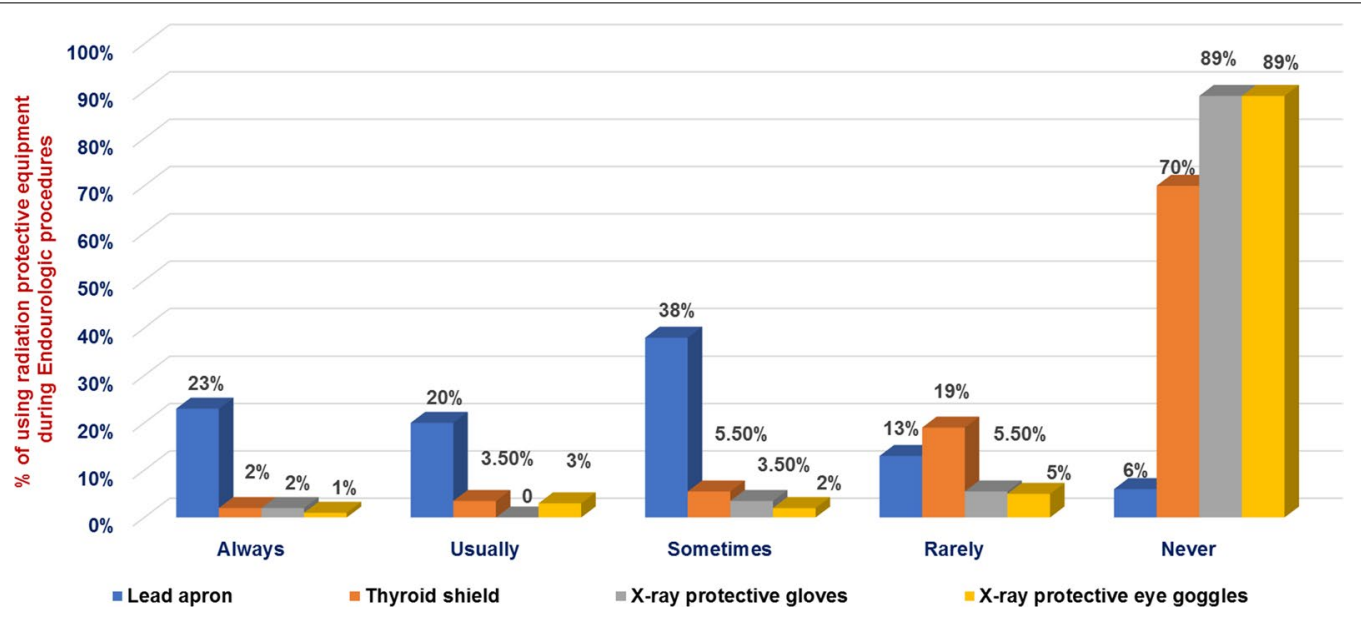

Fig. 1 Percentage of all participants who use radiation protective equipment in terms of lead aprons, thyroid shield, $X$-ray protective gloves and $X$-ray protective eye goggles during Endourologic procedures 
About 21\% reported incidents when nurses or urologists they know have been treated for X-ray exposure related diseases. Regarding the weight of the lead apron, $65 \%$ reported that they complain from its weight, and $37 \%$ mentioned that the lead apron heavy weight would refrain them from wearing it. Also, about $21 \%$ of urologist reported receiving food supplement prepared to counteract the radiation exposure by their hospitals (Table 1).

Compared with residents and specialists and consultants, professors reported the lowest FT during PCNL $(433 \pm 384,542 \pm 751,309 \pm 220$ vs. $194 \pm 167 \mathrm{~s} ; p=0.01)$, respectively. Nevertheless, the FT was comparable among residents, specialists, consultants and professors during the URS and JJ insertion ( $p$ values $>0.05$ ).

Compared with participants who did not receive radiation safety course, participants who received radiation safety course had significantly shorter FT during URS $(31 \pm 17$ vs. $131 \pm 181 ; p=0.04)$, PCNL $(137 \pm 84$ vs.
$413 \pm 556 ; p=0.03)$ and $\mathrm{JJ}$ insertion $(14 \pm 4$ vs. $65 \pm 102$; $p=0.04$ ) (Table 2). Furthermore, participants who received radiation safety course were significantly more compliant for "always using the lead apron" (67\% vs. $20 \%$; $p=0.02$ ). In addition, the number of years of experience $(<5 \mathrm{y}, 5-10 \mathrm{y}, 10-15 \mathrm{y},>15 \mathrm{y})$ and the current job level (resident, specialist, consultant, professor) was significantly associated with the compliance for wearing lead aprons $(p=0.006, p<0.001)$ (Figs. 2, 3). On regression analysis, previous radiation safety awareness courses was the only predictor of good compliance with radiation safety measures $(\mathrm{OR}=2 \pm 0.73, p=0.009)$.

\section{Discussion}

Fluoroscopy is considered an integral part of modern Endourology practice, especially Retrograde Intra-Renal Surgery and PCNL. In addition, there is continuing rise in the Urology diseases which require ionizing radiation,

Table 2 Comparison between participants who received radiation safety course and participants who did not receive radiation safety course in terms of the ability to reduce fluoroscopy time during Endourologic procedures

\begin{tabular}{|c|c|c|c|c|}
\hline & & $\begin{array}{l}\text { Participants who received } \\
\text { radiation safety course (9) }\end{array}$ & $\begin{array}{l}\text { Participants who didn't } \\
\text { receive radiation safety } \\
\text { course (133) }\end{array}$ & $p$ Value \\
\hline \multicolumn{2}{|c|}{ Mean hours of fluoroscopy guided endourologic procedures per week? } & $5.7 \pm 4.4$ & $4.2 \pm 6.2$ & 0.1 \\
\hline \multirow[t]{2}{*}{ URS } & URS/Week & $5(2.5-8.5)$ & $4(2.5-5)$ & 0.3 \\
\hline & $\begin{array}{l}\text { Fluoroscopy time (FT) in seconds } \\
\text { during URS }\end{array}$ & $31 \pm 17$ & $131 \pm 181$ & 0.04 \\
\hline \multirow[t]{2}{*}{ PCNL } & PCNL/Week & $2(1-3)$ & $1(1-2)$ & 0.2 \\
\hline & FT in seconds during PCNL & $137 \pm 84$ & $413 \pm 556$ & 0.03 \\
\hline \multirow[t]{2}{*}{ Double $J(J)$ insertion } & $J$ insertion/Week & $6(4-10)$ & $4(2-6)$ & 0.1 \\
\hline & FT in seconds during $\mathrm{JJ}$ insertion & $14 \pm 4$ & $65 \pm 102$ & 0.04 \\
\hline
\end{tabular}

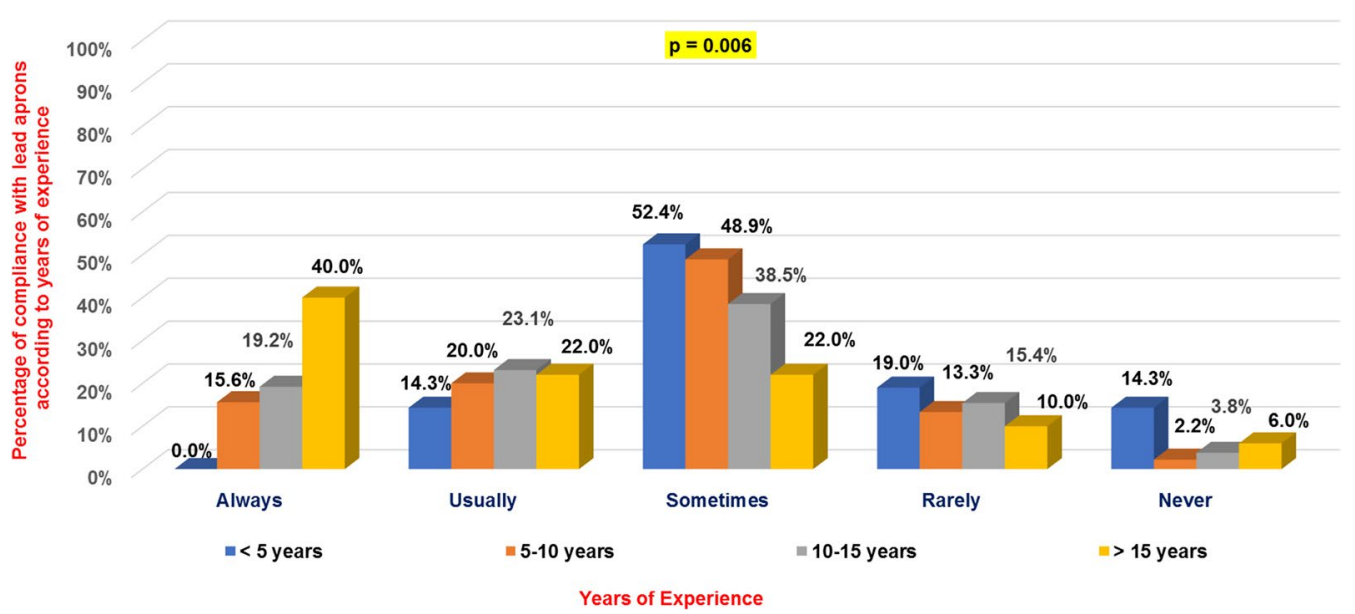

Fig. 2 Percentage of compliance with lead aprons according to the years of experience 


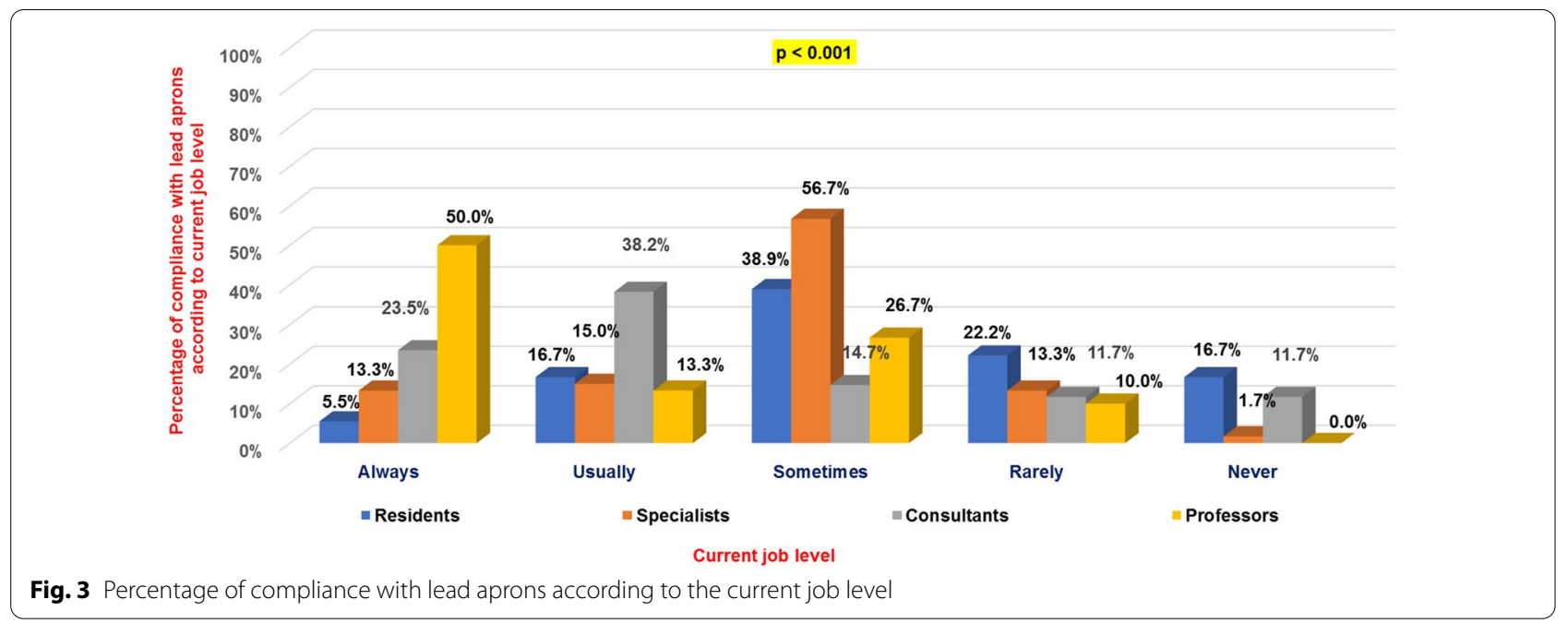

either for diagnosis or treatment [1]. This raised the concern about the potential hazards from radiation exposure in modern Urology practice, and the ways Urologists are protecting themselves. In one study, ionizing radiation from medical sources was increased 6 times in the United States from 1982 to 2006 [20]. For instance, the mean effective radiation dose (ERD) was estimated between $0.82-26.0 \mathrm{mSv}$ (average $9.2 \mathrm{mSv}$ ) during PCNL and higher doses correlated with increased stone burden, prolonged operative time, multiple punctures and blood loss $>250$ cc [21-23]. Despite all strategies which were described and were found to decrease Fluoroscopy exposure, such as ALARA principle, last image technology, pulsed fluoroscopy, and foot pedal control, the use of protective equipment is still vital and can lead to significantly lower radiation exposure as the use of lead apron lead to $96.5-99.5 \%$ attenuation of radiation, and the use of thyroid shield can decrease radiation exposure 23 times [7]. We conducted this survey to assess the awareness, training and implementation of ionizing radiation safety measures among Egyptian trainees and urologists and evaluate the safety measures taken during diagnosis and treatment in urology practice in Egypt. In the current study, we had considerable number of responses from residents, specialists, consultants and professors. Regarding wearing protective lead apron during $\mathrm{C}$-arm exposure, $23 \%$ reported that they always wear it, $38 \%$ sometimes wear it, and 13\% rarely wear it. In terms of the thyroid shield and X-ray protective gloves and eye googles, $70 \%$ and $89 \%$ and $89 \%$ reported that they never wear it, respectively. Compared with participants who did not receive radiation safety course, participants who received radiation safety course had significantly shorter FT during URS ( $31 \pm 17$ vs. $131 \pm 181)$, PCNL $(137 \pm 84$ vs. $413 \pm 556)$ and JJ insertion (14 \pm 4 vs. $65 \pm 102)$.
In the ESUT/EULIS survey, Tzelves and co-investigators assessed the knowledge and compliance to wearing ionizing radiation protective equipment among all attendees of 3 endourological meetings that took place in different European Countries between 2017 and 2018. They found good compliance with lead aprons $(89.6 \%)$ and thyroid shields (84.4\%), and very poor compliance with eye goggles (14.7\%) and gloves (8.1\%) [24]. In a study on Turkish Urology trainees and Urologists, the compliance with lead aprons was $75.24 \%$, thyroid shields was $46.44 \%$, eye goggles was $76.95 \%$, and protective gloves was $66.67 \%$ [18]. Both studies showed higher compliance with lead aprons and thyroid shields compared with the current study.

Interestingly, respondents who received lectures on radiation safety in Tzelves et al. study were more compliant [24]. This was congruent with the results in the current study where previous radiation safety course was the only predictor of better compliance with radiation safety measures, and participants who received radiation safety courses were two fold more compliant that those who did not receive radiation safety courses $(\mathrm{OR}=2 \pm 0.73$, $p=0.009$ ). Furthermore, Tzelves et al. did not find an association between the level of experience and the use of radiation safety measure [24], which coincide with the results of the current study.

In addition, Tzelves et al. study reported that $25 \%$ of responders received radiation safety lectures, while only $6 \%$ in our study received radiation safety course. The compliance with radiation safety equipment among endourological society members was investigated by Elkoushy and colleagues, and compliance rate was 97\% for lead aprons, $68 \%$ for thyroid shields, $9.7 \%$ for protective gloves, and $17.2 \%$ for eye goggles [25]. This shows the severity of lack of radiation safety equipment 
use among Egyptian Urology trainees and Urologists. In Elkoushy et al. study, $64 \%$ of urologists suffered from orthopedic problems [25]. This finding explains the suffering from the heavy weight of Lead aprons and the need to have lighter ones to increase the compliance to wear it. This finding was similar to the current study where the $65 \%$ of participants reported that they complain from heavy weight of Lead aprons, and 37\% mentioned that the heavy weight would refrain them from wearing it.

In the current study, professors reported significantly shorted FT compared with other groups of residents, specialists and consultants. This may be explained by the fact that academic institutions might offer better exposure for radiation safety measures and practices. Another explanation is that professors are academic staff, and they are used to attend international meetings, and they might have received some information about radiation safety measures during these meetings.

In another study by Harris and colleagues, a survey was sent to program directors for all Urology training programs in the US to assess radiation safety awareness among urology. Out of 136 respondents, only 46\% reported that radiation safety was part of their curriculum, $94 \%$ believed that infertility was potentially related to ionizing radiation exposure [16]. In our study, only $70 \%$ reported a relationship between ionizing radiation and the function of the gonads. Furthermore, US residents showed excellent compliance for Lead aprons (97\%) and thyroid shields (99\%) [16]. In Another study on Urology residents from twenty European countries, the compliance with Lead aprons was $75 \%$, and $55 \%$ of respondents received radiation safety education, and only $50 \%$ know ALARA principle [15]. In our study, ALARA principle was only known by $24 \%$ of participants. Furthermore, another study showed that only $15 \%$ of Indian Urology residents received radiation safety education and $60 \%$ use radiation safety protective equipment [1s7].

This study has several limitations as bias may result from the nature of respondents whether they were from radiation safety lovers or haters. Another bias may result from the non-equality in the distribution of responders from residents, specialists, consultants and professors, and the group with previous radiation safety course was only $6 \%$. In addition, participants with higher experience such as professors might have reported shorter FT. Finally, this questionnaire is not validated but it was created by experts in the field. Nevertheless, this is the first study to provide this detailed analysis of the effect of radiation safety courses on the adoption of radiation safety measures. Also, it carries a strong message and recommendation to all Urology program directors to include radiation safety lectures in the curricula and to all
Urology associations to include radiation safety courses in their annual meetings.

\section{Conclusion}

There was a lack of radiation safety awareness among Egyptian Urology Trainees and Urologist. Respondents who received radiation safety course showed significantly shorter FT during Endourologic procedures, and previous radiation safety course was the only predictor of better compliance with radiation safety measures. We encourage all Urology program directors to include radiation safety lectures in the curricula, and the EUA and Urology associations to include radiation safety courses in their annual meetings.

\section{Abbreviations}

ALARA: As low as reasonably achievable; CTUT: Computed tomography urinary tract; ESUT: EAU section of uro-technology; EULIS: EAU section of urolithiasis; FT: Fluoroscopy Time; IQR: Inter-quartile range; PCNL: Percutaneous nephrolithotomy; URS: Ureteroscopy.

\section{Acknowledgements}

Authors would like to thank the Egyptian Urological Association and all Egyptian Urologists who responded to this survey.

\section{Authors' contributions}

MO: Study design, data collection, data analysis, manuscript writing. EAAD: Study design and Manuscript writing. BE: Study design and Manuscript writing. AES: Data collection and manuscript writing. YN: Study design, data collection, data analysis and manuscript editing. All authors read and approved the final manuscript.

\section{Funding}

None.

\section{Availability of data and material}

The datasets used and/or analysed during the current study are available from the corresponding author on reasonable request.

\section{Ethics approval and consent to participate}

This study was approved by the Egyptian Urological Association. Response to this survey was considered a consent to participate in this study.

\section{Consent for publication}

Not applicable.

\section{Competing interests}

The authors declare that they have no competing interests.

\section{Author details}

${ }^{1}$ Department of Urology, Menoufiya University Hospital, Menoufiya, Egypt.

${ }^{2}$ Department of Urology, Zagazig University Hospital, Zagazig, Egypt.

${ }^{3}$ Department of Urology, Benha Faculty of Medicine, Benha University, Benha 13511, Egypt.

Received: 9 October 2020 Accepted: 25 December 2020

Published online: 11 January 2021

\section{References}

1. Scales CD Jr, Smith AC, Hanley JM, Saigal CS (2012) Urologic diseases in America project prevalence of kidney stones in the United States. Eur Urol. 62(1):160-5 
2. Turney BW, Reynard JM, Noble JG, Keoghane SR (2012 Apr) Trends in urological stone disease. BJU Int 109(7):1082-1087

3. Schauer DA, Linton OW (2009) National council on radiation protection and measurements report shows substantial medical exposure increase. Radiology 253(2):293-296

4. US FDA (2020) Initiative to reduce unnecessary radiation exposure from medical imaging. 2010. Accessed on April 15 2020. http://www.fda.gov/ downloads/Radiation-EmittingProducts/RadiationSafety/RadiationD oseReduction/UCM200087.pdf

5. Chodick G, Bekiroglu N, Hauptmann M et al (2008) Risk of cataract after exposure to low doses of ionizing radiation: a 20-year prospective cohort study among US radiologic technologists. Am J Epidemiol 168:620-631

6. Sont WN, Zielinski JM, Ashmore JP et al (2001) First analysis of cancer incidence and occupational radiation exposure based on the National Dose Registry of Canada. Am J Epidemiol 153:309-318

7. Noureldin YA, Andonian S. Radiation Safety during Diagnosis and Treatment (chapter), In: Textbook of Smith's Textbook of Endourology (4th edition). Editors: Arthur Smith, Glenn Preminger, Louis Kavoussi, and Global Badlani. Wiley Blackwell, pp. 14-37 (2019)

8. Leuraud K, Richardson DB, Cardis E, Daniels RD, Gillies M, O'Hagan JA, Hamra GB et al (2015 Jul) lonising radiation and risk of death from leukaemia and lymphoma in radiation-monitored workers (INWORKS): an international cohort study. Lancet Haematol 2(7):e276-e281

9. Richardson DB, Cardis E, Daniels RD, Gillies M, O'Hagan JA, Hamra GB, Haylock R et al (2015 Oct) Risk of cancer from occupational exposure to ionising radiation: retrospective cohort study of workers in France, the United Kingdom, and the United States (INWORKS). BMJ 20(351):h5359

10. Wrixon AD (2008) New ICRP recommendations. J Radiol Prot 28:161-168

11. Huang GO, Engebretsen SR, Smith JC, Wallner CL, Culpepper DJ, Creech JD et al (2014) Detection of uric acid stones in the ureter using low and Conventional dose computed tomography. Urology. 84:571-574

12. Elkoushy MA, Shahrour W, Andonian S (2012) Pulsed fluoroscopy in ureteroscopy and percutaneous nephrolithotomy. Urology 79(6):1230-1235

13. Mohey A, Alhefnawy M, Mahmoud M, Gomaa R, Soliman T et al (2018 Feb) Fluoroless-ureteroscopy for definitive management of distal ureteral calculi: randomized controlled trial. Can J Urol 25(1):9205-9209

14. Zhou T, Chen G, Gao X, Zhang W, Xu C, Li L, Sun Y (2015) 'X-ray'-free balloon dilation for totally ultrasound-guided percutaneous nephrolithotomy. Urolithiasis. 43(2):189-95

15. Söylemez H, Sancaktutar AA, Silay MS, Penbegül N et al (2013 Jan) Knowledge and attitude of European urology residents about ionizing radiation. Urology 81(1):30-35
16. Harris AM, Loomis J, Hopkins M, Bylund J (2019) Assessment of radiation safety knowledge among urology residents in the United States. J Endourol. 33(6):492-497

17. Jindal T (2015) The knowledge of radiation and the attitude towards radio-protection among urology residents in India. J Clin Diagn Res. https ://doi.org/10.7860/JCDR/2015/14004.6968

18. Söylemez H, Altunoluk B, Bozkurt $Y$, Sancaktutar AA, Penbegül $N$ et al (2012 Apr) Radiation exposure-do urologists take it seriously in Turkey? J Urol 187(4):1301-1305

19. Tok A, Akbas A, Aytan N, Aliskan T, Cicekbilek I, Kaba M et al (2015) Are the urology operating room personnel aware about the ionizing radiation? Int Braz J Urol. 41(5):982-9. https://doi.org/10.1590/S1677-5538

20. Mettler FA Jr, Thomadsen BR, Bhargavan MM et al (2006) Medical radiation exposure in the U.S. in 2006: preliminary results preliminary results. Health Phys 2008(95):502-507

21. Safak M, Olgar T, Bor D, Berkmen G, Gogus C (2009) Radiation doses of patients and urologists during percutaneous nephrolithotomy. J Radiol Prot 29(3):409-415

22. Mancini JG, Raymundo EM, Lipkin M et al (2010) Factors affecting patient radiation exposure during percutaneous nephrolithotomy. J Urol 184(6):2373

23. Noureldin YA, Elkoushy MA, Andonian S (2015) Predictors of fluoroscopy time during percutaneous nephrolithotomy: impact of postgraduate urology trainees and STONE Nephrolithometry score. J Endourol. 29(5):542-7

24. Tzelves L, Somani B, Knoll T, Kamphuis G, Sarica K et al (2020 Mar) Level of knowledge on radiation exposure and compliance to wearing protective equipment: where do endourologists stand? An ESUT/EULIS Survey. World J Urol 38(3):761-768

25. Elkoushy MA, Andonian S (2011 Oct) Prevalence of orthopedic complaints among endourologists and their compliance with radiation safety measures. J Endourol 25(10):1609-1613

\section{Publisher's note}

Springer Nature remains neutral with regard to jurisdictional claims in published maps and institutional affiliations.

\section{Submit your manuscript to a SpringerOpen ${ }^{\circ}$ journal and benefit from:}

- Convenient online submission

- Rigorous peer review

- Open access: articles freely available online

- High visibility within the field

- Retaining the copyright to your article

Submit your next manuscript at $\boldsymbol{\nabla}$ springeropen.com 